\title{
Distribution of ore minerals in banded epithermal veins: Results of micro-X-ray fluorescence mapping
}

ERIK R. THARALSON ${ }^{1 *}$, NigEL M. KELLY ${ }^{1,2}$, THOMAS MONECKE ${ }^{1}$, KATHARINA PFAFF ${ }^{1}$, T. JAMES REYNOLDS ${ }^{3}$, AND LAUREN ZEECK ${ }^{1}$

${ }^{1}$ Center for Mineral Resources Science, Colorado School of Mines, Golden, CO 80401, USA (*correspondence: etharals@mines.edu)

${ }^{2}$ Bruker Nano Analytics, Kennewick, WA 99336, USA (nigel.kelly@bruker.com)

\section{${ }^{3}$ FLUID INC., Denver, CO 80202, USA}

Low-sulfidation epithermal deposits are significant sources of $\mathrm{Au}$ and $\mathrm{Ag}$. The deposits are formed in the shallow subsurface by near-neutral chloride waters that are of low salinity $(<3-4$ wt.\% $\mathrm{NaCl})$. However, the distribution of precious metals is not uniform, with only discrete quartz bands containing ore minerals. Understanding the distribution of ore minerals and their associations with quartz textures is key to understanding the processes associated with precious metal formation in low-sulfidation epithermal deposits.

Micro-X-ray fluorescence ( $\mu \mathrm{XRF}$ ) mapping was conducted on a number of representative ore samples from deposits worldwide to characterize the distribution of ore minerals and to study metal associations within the bands. The $\mu$ XRF maps (e.g., Fig 1) show that Au and Ag commonly occur together in light grey quartz bands, which are widely referred to as ginguro bands. However, Au also occurs in separate discrete white quartz bands (referred to as gankin bands) that lack Ag-rich phases. Focused investigation of the ore-bearing ginguro and gankin bands show they are characterized by the presence of fine-grained mosaic quartz with subtle textures of preexisting microspheres, which is interpreted to have formed as a result of flashing of the ore-forming fluids.

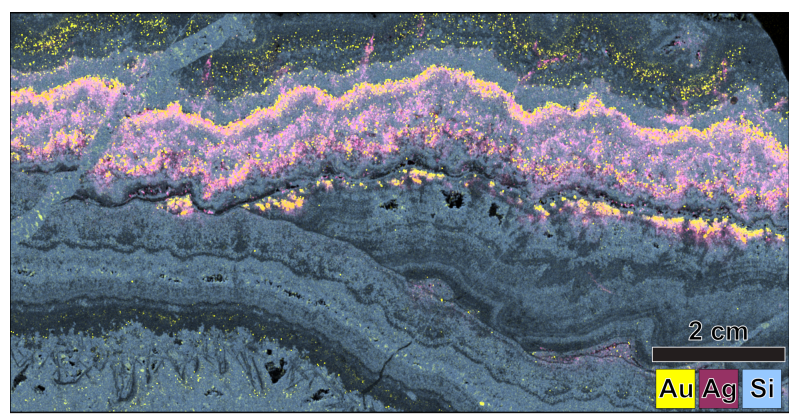

Figure 1: Composite $\mathrm{Au}-\mathrm{Ag}$-Si element map of a banded vein sample from the Sado deposit, Japan. 